\title{
O PROCESSO DE VERIDICÇÃO E GOVERNAMENTALIDADE PLANETÁRIA NO COMBATE AO TERRORISMO DURANTE O GOVERNO GEORGE W. BUSH'
}

\author{
THE VERIDICTION PROCESS AND PLANETARY GOVERNAMENTALITY IN \\ SECURITIZATION OF TERRORISM DURING THE GEORGE W. BUSH \\ ADMINISTRATION
}

DOI: $10.5380 /$ cg.v9i2.74990

Tadeu Morato Maciel²

Paulo Roberto da Silva Vieira3

\begin{abstract}
Resumo
O imediato pós-Guerra Fria inaugurou um período repleto de novos conflitos em âmbito global, os quais se estruturavam em uma lógica diferente da perspectiva tradicional de embates interestatais. Estes atritos têm, dentre suas características principais, a atuação de atores não-estatais e o caráter transterritorial das novas ameaças à governança global, como é possível observar no terrorismo contemporâneo. Atentos a essa dinâmica e tendo como base as contribuições analítico-metodológicas de Michel Foucault à análise do discurso, nesse artigo propomos examinar em que medida o processo de veridicção - enquanto construção de "regimes de verdade" - embasou as ações do governo norte-americano de George W. Bush contra grupos definidos como terroristas fundamentalistas. Tendo como hipótese que os novos dispositivos de segurança são formulados com o intuito de instaurar um policiamento que não se restringe ao âmbito interno de certos Estados, apropriamo-nos das noções de "governamentalidade" de Foucault (2016) e de "dispositivo diplomáticopolicial" de Rodrigues (2013) para indicar a transterritorialidade das políticas de segurança voltadas ao terrorismo. De forma específica, investigamos, a partir do Patriot Act (2001) e da National Security Strategy (2002), em que medida os discursos contribuem para a formulação das políticas de segurança estadunidense, favorecendo o estabelecimento de uma governamentalidade planetária ancorada em ações de repressão, prevenção e controle sob determinados grupos e populações comumente associados ao terrorismo. Nesse sentido, observamos como o fortalecimento do status de verdade para determinados discursos sobre o terrorismo contemporâneo permite a materialização de práticas de policiamento de condutas (dispositivo diplomático-policial) em prol de uma segurança planetária.
\end{abstract}

Palavras-Chave: Terrorismo; Regimes de Verdade; Dispositivo diplomático-policial; Governo Bush; Governamentalidade Planetária.

\begin{abstract}
The immediate post-Cold War inaugurated a period full of new conflicts at a global level, which were structured in a different logic from the traditional perspective of interstate clashes. These frictions have among their main characteristics the role of non-state actors and the transterritorial character of the new threats to global

\footnotetext{
${ }^{1}$ Este artigo foi originado de uma pesquisa financiada com recursos da Coordenação de Aperfeiçoamento de Pessoal de Nível Superior (CAPES).

2 Professor Colaborador e Pós-doutorando no Instituto de Estudos Estratégicos (INEST) da Universidade Federal Fluminense (UFF). E-mail: tadeummaciel@gmail.com. ORCID: http://orcid.org/o000-0003-25914557 .

3 Mestrando no Programa de Pós-Graduação em Estudos Estratégicos da Defesa e Segurança (PPGEST) da Universidade Federal Fluminense. E-mail: mpr_vieira@id.uff.br. ORCID: https://orcid.org/oooo-ooo26118-0004.
} 
governance, as can be seen in contemporary terrorism. Attentive to this dynamic and based on Michel Foucault's analytical-methodological contributions to discourse analysis, in this article we propose to analyze the extent to which the veridiction process - as construction of "truth regimes" - supported the actions of the US government of George W. Bush against groups defined as fundamentalist terrorists. Having the hypothesis that the new security devices are formulated in order to establish policing actions that is not restricted to the internal scope of certain States, we appropriate the notions of "governmentality" by Foucault (2016) and "diplomatic-police device" by Rodrigues (2013) to indicate the transterritoriality of security policies targeting terrorism. Specifically, we investigate the Patriot Act (2001) and the National Security Strategy (2002) to verify the speeches contribute to the formulation of US security policies, favoring the establishment of a planetary governmentality anchored in repression actions, prevention and control under certain groups and populations commonly associated with terrorism. In this sense, we observe how the strengthening of the status of truth for certain discourses about contemporary terrorism allows the materialization of conduct policing practices (diplomatic-police device) in favor of planetary security.

Keywords: Terrorism; Truth Regimes; Diplomatic-police device; Bush Administration; Planetary Governmentality.

\section{INTRODUÇÃO}

No mundo contemporâneo, as ameaças terroristas têm aparecido como tema frequente na mídia, em políticas governamentais e em estudos acadêmicos das mais diversas vertentes teóricas. Principalmente a partir dos atentados de 11 de setembro de 2001, reacendeu a preocupação com a segurança em relação ao perigo que o terror proporcionaria às esferas política, econômica e social. Embora seja possível encontrar precedentes imediatos dessa dinâmica em eventos na década de 1990, entende-se que, com os acontecimentos ocorridos nos Estados Unidos (EUA) em 2001, as políticas de segurança associadas ao terrorismo tornaram-se mais presentes e expressivas no contexto global4.

Neste período, em meio aos fluxos transterritoriais legais e ilegais, verifica-se a crescente dificuldade em compreender os espaços nacionais e o âmbito internacional de forma estanque (WALKER, 2013). Se anteriormente o terror era associado à luta de grupos associados a determinado contexto local, na contemporaneidade a transterritorialidade será uma característica que transformará o terrorismo em um "inimigo insolúvel”, que apresenta uma resistência mais forte do que no passado (DUARTE, 2014). Nesse sentido, o terrorismo fundamentalista é a expressão contemporânea de um fenômeno muito mais complexo (PROCÓPIO, 2001).

A despeito da frequência com que a expressão "terrorismo" tem sido acionada atualmente, sua definição permanece bastante difícil e contestada, sendo evidente os múltiplos significados que tal termo tem assumido ao longo da história. Apesar de suas diversas procedências, geralmente o fenômeno do terrorismo tem sido associado à imagem do caos e, frequentemente, culminaria em um ambiente de pânico generalizado, devido à morte e à destruição causadas por ele. Neste sentido, a própria imprecisão do termo é um fator que dificulta as análises de pesquisadores dessa temática,

\footnotetext{
4 Em setembro de 2001, os EUA foram atingidos por ataques coordenados pela organização al-Qaeda. Quatro aviões comerciais foram sequestrados, sendo que dois foram lançados contra o World Trade Center (WTC), um contra o Pentágono e o último caiu em um campo aberto na Pensilvânia.
} 
pois os terrorismos na era moderna foram caracterizados por especificidades que são distintas daquelas observadas no século XXI (SEIXAS, 2008).

Na perspectiva deste texto, uma parte relevante da imprecisão acerca do termo terrorismo é desenvolvida a partir de uma tentativa de busca objetiva de uma suposta natureza para esse fenômeno. Portanto, a principal premissa que fomenta esta análise é a de que "não existe uma 'ontologia' do terrorismo, ou seja, não há uma 'essência' ou 'natureza' do terrorismo" (RODRIGUES e KALIL FILHO, 2018, p. 42). Historicamente, as ideias de Terror e terrorismo possuem importantes procedências associadas à Revolução Francesa. Neste período, o grupo político formado por pequenos burgueses, denominados de jacobinos, liderados por Robespierre, implementou o uso da violência como uma forma legítima de zelar pela coisa pública, tendo, por conseguinte, forte influência na formação dos direitos civis (DUARTE, 2014, p. 27). Tendo em vista essa dinâmica, é preciso ressaltar que a valoração positiva ligada à "Era do Terror" jacobina é substituída por uma visão de ilegitimidade dos movimentos subsequentes, entre eles, o terrorismo fundamentalista.

Neste ponto, torna-se fundamental a análise dos discursos que fomentam as definições acerca dos termos em questão, pois, a partir de uma analítica foucaultiana enquanto inspiração teórico-metodológica, compreende-se que a construção de determinado discurso estabelece o que o Foucault denomina de "regimes de verdade". De acordo com Foucault (2010a, p. 67), regimes de verdade implicam naquilo "que constrange os indivíduos a um certo número de atos de verdade", estabelecendo, para tais atos, certas condições e efeitos específicos. Portanto, considerando que a produção de saberes e verdades são construídas, entende-se que examinar quem produz o discurso e, concomitantemente, qual a intencionalidade deste agente é fulcral para a compreensão do que está sendo definido como terrorismo.

A partir desta perspectiva, a construção do "verdadeiro" é determinada por valores e ideias que moldam a caracterização do ato (terrorismo) e do sujeito (terrorista), culminando em uma luta constante entre "produções de verdade". Segundo Rodrigues e Kalil Filho (2018), a disputa entre produções de verdade pode ser evidenciada nas enunciações proferidas tanto pelos Estados Unidos, quanto por Osama bin Laden, pois nota-se que, do lado estadunidense, Bush evocava um discurso estruturado em um pilar religioso cristão para justificar o emprego militar no combate ao infiel fundamentalista e, por outro lado, bin Laden defendia a Jihad como guerra justa em contraposição às agressões ocidentais.

Assim sendo, a proposta deste artigo é averiguar em que medida a construção destes regimes de verdade - entendido por Foucault (2010b) como processo de veridicção - pode ser associada ao (re)posicionamento do terrorismo enquanto um problema de segurança dos EUA. Tal análise nos permite demonstrar que não há fenômenos inerentemente "de segurança" ou agentes, valores e práticas essencialmente "perigosos". Pelo contrário, determinados grupos, temas e iniciativas são identificados como "ameaças" por meio dos embates estabelecidos entre determinados discursos e 
os "regimes de verdade" resultantes desse processo, através dos quais se verifica os discursos que devem ser encampados e os que devem ser combatidos.

Vale ressaltar que este artigo não é caracterizado pelo objetivo de afirmar se certo discurso é falso ou verdadeiro. Seguindo a perspectiva teórica de que todos os discursos são parciais e perspectivos, o objetivo é verificar como algumas práticas são acionadas em nome de uma determinada definição de terrorismo. Tendo como hipótese que os novos dispositivos de segurança são formulados com o intuito de instaurar um policiamento que não se restringe ao âmbito interno de certos Estados - mas se alastra enquanto uma governamentalidade em âmbito planetário (PASSETTI, 2013; RODRIGUES, 2013) - este texto pretende investigar, a partir da análise do Patriot Act (2001) e da National Security Strategy (2002), as relações entre o processo de veridicção no discurso estadunidense acerca do terrorismo e o seu (re)posicionamento enquanto uma questão de segurança a nível global.

Dessa forma, o texto está estruturado sob dois tópicos principais. No primeiro é discutida a gênese do terrorismo contemporâneo em meio às novas dinâmicas da segurança internacional no pós-Guerra Fria. Nesse mesmo tópico será indicado como a noção de veridicção nos auxilia a compreender as diversas versões sobre o que é o terrorismo enquanto construção de "verdades", o que impossibilitaria uma definição estanque sobre essa questão, visto que qualquer conceitualização sobre o terrorismo é embebida por valores e interesses políticos. No tópico seguinte, será feita uma análise mais detida do Patriot Act e da National Security Strategy dos EUA, enquanto exemplo do estabelecimento desses regimes de verdades.

\section{O TERRORISMO ENQUANTO AMEAÇA À SEGURANÇA INTERNACIONAL NO SÉCULO XXI A PARTIR DA PERSPECTIVA DE VERIDICÇÃO}

A partir do soçobrar da Guerra Fria, no final da década de 1980, diversos representantes do internacionalismo liberal, como Francis Fukuyama (1992), forneceram ênfase à chamada "teoria da paz democrática”, ao acreditarem que a nova conjuntura internacional seria marcada por uma paz duradoura, balizada em princípios liberais e democráticos ${ }^{5}$. Este período ficou marcado pela ascensão de conflitos sob uma nova estrutura, que se difere da perspectiva tradicional clausewitziana, baseada no embate entre Estados. O fim do conflito bipolar que caracterizou a Guerra Fria possibilitou o estabelecimento de novos entendimentos sobre quais seriam os atuais constrangimentos à ordem internacional. Mais do que isso, rediscutia-se qual deveria ser o foco da segurança, ou seja, qual era o agente básico a ser protegido.

\footnotetext{
5 Em síntese, os defensores da "teoria da paz democrática" afirmam que os Estados democráticos seriam mais cooperativos e menos propensos a iniciarem enfrentamentos (inclusive não combateriam entre si).
} 
Segundo o Relatório de Desenvolvimento Humano de 1994 do Programa das Nações Unidas para o Desenvolvimento (PNUD), intitulado "Novas Dimensões da Segurança Humana", o conceito de segurança havia sido interpretado de maneira limitada por muito tempo, ao estar mais voltado à proteção dos Estados do que das pessoas. "Com o recuo das escuras sombras da Guerra Fria, podese notar que muitos conflitos são dentro de nações ao invés de serem entre nações (PNUD, 1994, p. 22). Consequentemente, também ascendia um novo rol de ações que deveriam ser adotadas pelos mais diversos atores internacionais em relação às "novas ameaças” à governança global.

Nesse cenário, evidenciava-se o fortalecimento de novos modelos de conflitos, denominados por Mary Kaldor (2012) de "novas guerras" (new wars), contrapondo-se às denominadas "velhas guerras" (old wars). As velhas guerras representariam a estrutura clássica proposta por Carl Von Clausewitz, isto é, embates tradicionalmente interestatais nos quais os Estados teriam a guerra como instrumento político para compelir o outro à sua vontade (CLAUSEWITZ, 1989). Enquanto isso, as novas guerras simbolizariam o crescente limite do controle estatal em relação aos embates armados, acompanhado pela presença de atores não estatais como novos agentes dos conflitos. Segundo Kaldor (2012), as novas guerras devem ser entendidas a partir do conceito de deslocamento global, pois essas estruturas compartilham novas formas de luta pelo poder, baseadas em uma dinâmica relação entre atores estatais e não estatais. Além disso, a autora elenca dois fatores fundamentais para a apreensão desta estrutura contemporânea de conflitos, sendo eles: a globalização $e$ as políticas identitárias.

A globalização é importante, pois, segundo Kaldor (2012), ela possui alguns pontos relevantes na formação desta nova estrutura de conflitos. Primeiro, ressalta-se a transnacionalização e regionalização da governança. Em segundo lugar, há a formulação de uma politização cosmopolita, operacionalizada por meio de instituições internacionais, organizações não governamentais, "valores humanos" (direitos políticos e sociais universais, paz e democracia). Em terceiro lugar, há uma noção de sociedade civil transnacional. Já as políticas identitárias são relacionadas ao que a autora define como "movimentos cuja mobilização ocorreria acerca da identidade étnica, racial ou religiosa" (KALDOR, 2012, p. 79). Além disso, ela reconhece que em áreas de conflito endêmico, essas políticas identitárias tendem a ser mais extremadas, ou seja, há uma probabilidade mais alta de se tornar um fundamentalismo.

À vista dessas novas estruturas de conflito enunciadas por Kaldor, torna-se perceptível a construção de um discurso antiocidental, fomentado por uma crítica à globalização e, posteriormente, a sua tentativa de transbordamento para o Oriente. Essa perspectiva foi basilar para grupos como a al-Qaeda, pois estes definiram seus alvos como sendo os "infiéis do Ocidente, que estariam subjugando-os por certa globalização forçada do modo de vida e da cultura ocidentais" (DUARTE, 2014, p. 45). Em relação às políticas identitárias, o fato do terrorismo fundamentalista se estruturar em premissas culturais, étnicas e religiosas faz com que esse fenômeno contemporâneo 
se enquadre nas considerações promovidas pela autora como características inerentes às novas guerras.

A eclosão dos ataques terroristas instaurou uma cultura de medo generalizado e, consequentemente, um sentimento de insegurança. Assim, após os atentados de 11/o9, os EUA passaram a liderar os movimentos contra o terror, tendo as invasões no Afeganistão e no Iraque como medidas imediatas e exemplares de combate ao terrorismo. Essas intervenções eram fundamentadas em um discurso antiterrorista que pôs, de forma justaposta, valores baseados em premissas democráticas ocidentais e imperativos religiosos. Em síntese, independentemente da causa moral defendida, seja ela teocrática ou democrática, o intuito em comum é justificar o uso da violência em prol de um bem maior (DUARTE, 2014).

A partir da sensação de insegurança potencializada por discursos voltados a definir quem seriam os terroristas fundamentalistas, tornou-se latente a construção de novas políticas de segurança em resposta ao fenômeno em questão. Mesmo que a ameaça não fosse efetiva, no campo discursivo ela foi definida como uma realidade inequívoca, o que foi suficiente para que as construções discursivas sobre o terrorismo resultassem em efeitos políticos substanciais. Dessa forma, a análise da construção dos discursos criados em torno da justificativa do combate ao terrorismo evidencia os interesses dos atores envolvidos nestas proposições linguísticas.

Por exemplo, na Guerra ao Terror - capitaneada pelo governo de George Walker Bush (20012009), após os atentados de 11 de setembro de 2001 - as sociedades que se consideravam alvo dos ataques adotaram legislações mais restritivas em nome da diminuição do perigo relacionado ao terrorismo:

Nas sociedades mais democráticas, a oportunidade tem sido usada para introduzir legislação dura e repressiva, para impor obediência à população, torná-la mais submissa, aumentar a autoridade do Estado. E também para colocar em prática programas que eles sabem que a população não aceitaria (CHOMSKY, 2003, p. 121).

Esse movimento de combate ao terrorismo islâmico foi instrumentalizado pela Doutrina Bush, uma política estabelecida através de documentos que formularam uma nova estratégia de segurança de combate aos grupos considerados fundamentalistas. Segundo Duarte, essa operação introduziu "mecanismos de combate e dispositivos de controle aos terroristas em escala global, sem limites de território ou soberania" (DUARTE, 2014, p. 51-52).

Destarte, na perspectiva deste artigo, é possível compreender a construção desse discurso antiterrorista a partir da concepção de regimes de verdade, conforme proposto por Michel Foucault (2016). A veridicção, ou seja, o processo de construção de verdades, é fundamental no estabelecimento destes dispositivos de segurança, pois, compreendendo a relação intrínseca entre poder-verdade-veridicção, a questão discursiva se torna importante para a compreensão das práticas derivadas destas construções. Sob este prisma analítico, Yazbek evidencia que: 
Tomando o discurso a partir de suas condições de enunciação e circulação, tratavase de explicitar os efeitos de exigência e coerção exercidos pela norma do verdadeiro nos domínios aos quais ela é aplicável. [...] Enunciados que terão como seu correlato indispensável práticas sociais e institucionais diversas (YAZBEK, 2013, p. 92).

Assim, é preciso atentar para o processo de normalização do comportamento excepcional dos EUA na Guerra ao Terror. Excepcionalidade essa que se tornou válida - na perspectiva dos agentes governamentais e de uma parcela significativa da sociedade - devido à percepção de uma ameaça existencial aos valores estadunidenses. De modo que o combate ao terrorismo passou a ser considerado um dever dos países que preservariam os valores universais do Ocidente, dentre eles, a liberdade. A construção deste discurso de preservação dos valores ocidentais foi crucial para fomentar as bases da Guerra ao Terror, sendo possível, ao explorar o tema sob uma perspectiva foucaultiana de poder-verdade, analisar pontos que são, algumas vezes, negligenciados por outras análises acerca do terrorismo (tais como os interesses e efeitos políticos de determinada conceitualização sobre o terrorismo, conforme exemplificaremos no próximo tópico).

A verdade, para Foucault (2016, p. 54), é um “conjunto de procedimentos regulados para a produção, a lei, a repartição, a circulação e o funcionamento dos enunciados" que "está circularmente ligada ao sistema de poder, que a produz e apoia, e a efeitos de poder que ela induz e que a reproduz, enquanto um 'regime' de verdade". Portanto, nesta perspectiva "não há poder sem regime de verdade; não há verdade sem regime de poder” (YAZBEK, 2013, p. 94). A noção de poder em Foucault difere da visão tradicional de mera tangibilidade do poder, isto é, a analítica foucaultiana compreende o poder como relacional, e não como uma "coisa" que poderia ser possuída. Seu exercício não é simplesmente algo que suprime comportamentos a partir da violência explícita, mas também produz condutas, ou seja, modos de agir e pensar. Em outras palavras, as relações de poder produziriam subjetividades, ou seja, produtos de relações histórico-políticas complexas que constituem o sujeito.

Ao se considerar que as construções dos discursos são permeadas por valores e conceitos entendidos como "verdadeiros", evidencia-se uma correlação de forças, à qual é denotada a noção de conflito agônico 6 , isto é, o embate de "relações de poder que buscam afirmar 'verdades' e/ou resistir a essa afirmação a partir da defesa de outras 'verdades"” (RODRIGUES e KALIL FILHO, 2018, p. 36). Segundo Foucault (2016, p.53), "há um combate 'pela verdade' ou, ao menos, 'em torno da verdade", e a esse verdadeiro atribui-se "efeitos específicos de poder".

Nesse sentido, o artigo se propõe a examinar esse processo de veridicção, tendo em vista que esses enfrentamentos possuem diferentes verdades, que disputam a todo momento a sua proeminência sobre a outra. Diante dessa visão agonística da construção de "regimes de verdade",

\footnotetext{
${ }^{6}$ Foucault (1995) indica que a subjetividade (como as individualidades das pessoas são constituídas) é produto de combates (ágon, em grego antigo) realizados cotidianamente por meio de relações de poder. No agonismo das forças, prevalece a "verdade" de quem triunfa nesses combates, permeados, muitas vezes, por violências implícitas e explícitas.
} 
entende-se a necessidade de examinar essa dinâmica de lutas como premissa "metodológica para analisar a produção de verdade e as formas discursivas pelas quais elas são enunciadas" (RODRIGUES e KALIL FILHO, 2018, p. 37). Vale ressaltar que, apesar deste artigo se debruçar mais especificamente sobre a "verdade estadunidense", não se pode negligenciar que esse discurso suscita resistências ao "enunciado vencedor" dos Estados Unidos.

Logo, ao analisar o terrorismo por uma perspectiva agonística da construção de verdades, admite-se que os discursos são produzidos e modificados ao longo do tempo, devido ao embate com outros enunciados que ocupam posições (políticas, éticas, etc.) distintas. Por este viés epistemológico, pode-se inferir que a "verdade" estadunidense acerca do combate ao terrorismo não é desinteressada e, ao mesmo tempo, possui um caráter determinante para as políticas de segurança desse período. Assim, os enunciadores de discursos (políticos, militares, diplomatas, acadêmicos, a mídia, etc.) afirmam sua "verdade" em relação às demais com o intuito de angariar legitimidade política e apoio popular que permitam alterações legais e ações militares que não seriam admitidas em outro cenário.

À vista disso, propõe-se examinar a construção dos documentos formulados pelos policymakers norte-americanos que procuravam, a partir desses elementos discursivos, legitimar as medidas que seriam utilizadas para evitar a “destruição da América”. Destacam-se, dentre eles, o Patriot Act e o National Security Strategy, os quais serão analisados no próximo tópico, enquanto forma de verificar a construção de "regimes de verdade" em relação ao terrorismo contemporâneo.

\section{A FORMULAÇÃO DO PATRIOT ACT E DA NATIONAL SECURITY STRATEGY ENQUANTO CONSTRUÇÃO DOS “REGIMES DE VERDADE”}

O governo de George W. Bush pode ser considerado um marco de intensa potencialização do terrorismo fundamentalista enquanto principal ameaça aos EUA. Analisar os documentos emitidos em seu primeiro mandato é crucial para a compreensão da Guerra ao Terror. Esse texto explora o processo de veridicção estruturado pelo Patriot Act, assim como pela National Security Strategy (NSS), ambos implementados como resposta aos ataques de 11 de setembro de 2001. Tais dispositivos legais foram essenciais para o redimensionamento e potencialização dos EUA enquanto "autoridade policial mundial", legitimando seus poderes extraordinários em meio ao "estado de exceção" fomentado pela Guerra ao Terror (GARDELL, 2008).

O Ato Patriota foi elaborado pelo Departament of Justice e emitido em 26 de outubro de 2001. A partir deste decreto, os EUA inauguraram diversas leis, documentos, reformas institucionais e decisões presidenciais que fomentaram a Guerra ao Terror. Dessa forma, o governo estadunidense procurou definir tanto jurídica quanto politicamente o que seria o fenômeno do terrorismo e, por conseguinte, estabelecer sanções, medidas repressivas, intervenções e ocupações militares. Para o 
Departamento de Justiça, a prioridade seria prevenir futuros ataques terroristas, pois a missão imprescindível era "proteger os americanos inocentes dos planos mortíferos cunhados pelos terroristas dedicados a destruir a América e o seu modo de vida” (US PATRIOT ACT, 2001, n.p). Posto isso, o Patriot Act seria parte chave deste processo de preservação da vida e da liberdade do povo americano diante dos desafios impostos pelas redes terroristas globais (US PATRIOT ACT, 2001).

Posteriormente à "Lei Patriota dos EUA", em 17 de setembro de 2002 a Casa Branca publicou a Estratégia de Segurança Nacional (NSS). O documento em questão ressaltava a preocupação com os fenômenos que ameaçavam os valores democráticos e liberais do país, tendo como enfoque o combate ao terrorismo fundamentalista. Segundo a NSS, a liberdade é uma demanda inegociável para a dignidade humana em todas as civilizações e, durante a história, ela tem sido ameaçada pela guerra e pelo terror. Portanto, sendo uma nação defensora da liberdade, os Estados Unidos receberiam a sua responsabilidade de liderar esta grande missão (NSS, 2002). As proposições basilares que moldavam esse discurso eram a defesa da liberdade, a democracia e o modo de vida estadunidense. Consequentemente, a vitória das "forças da liberdade" deveria ser a tônica do século XXI, sendo alguns países responsáveis pela luta por valores comuns - proteção dos direitos humanos e a liberdade (política e econômica) - dos freedom-loving contra os inimigos terroristas (NSS, 2002).

A construção deste inimigo externo e, por conseguinte, o fato de considerá-lo uma ameaça existencial para os valores estadunidenses transformaram-se no pilar das políticas de segurança de combate ao terrorismo no país. A partir da premissa de que há um inimigo que pode prejudicar diretamente a vida do cidadão, interpreta-se que existe a percepção generalizada de que este fenômeno é uma ameaça, sendo necessárias políticas mais restritivas e contundentes de combate a esse suposto risco crescente. A percepção trazida pela NSS de 2002 moldava um novo comportamento em relação ao combate do terrorismo fundamentalista, pois interpretava esse projeto como um fator de suma importância para a manutenção da paz. Nesta guerra contra o terror, os EUA deveriam exercer o papel de liderança, visto que o país gozava de uma posição inigualável de forças militares, além de influência política e econômica que seriam fulcrais nessa tentativa de normalização da ordem internacional. Todavia, essa força não seria utilizada de forma unilateral e sim para construir boas relações com as grandes potências, com o intuito de defender a paz e estendê-la para todos os continentes (NSS, 2002).

Neste âmbito de cooperação, segundo a NSS (2002, p. 29), as forças militares estadunidenses visariam: (1) assegurar seus aliados e amigos; (2) dissuadir futuras competições militares; (3) impedir ameaças que contrariam os interesses dos EUA, aliados e amigos; e (4) derrotar qualquer adversário, caso a dissuasão falhasse. Entretanto, os próprios formuladores do documento, os quais assumem que respeitarão os valores, julgamentos e interesses dos amigos e parceiros, afirmam que 
os EUA estarão preparados para atuar de forma separada quando seus interesses e reponsabilidades específicas forem requeridos (idem, p. 31).

Nesta guerra contra o terrorismo fundamentalista, na qual os EUA adotaram uma postura de liderança, é perceptível o estabelecimento de dispositivos de segurança que culminaram em uma administração das populações e, por consequência, seu controle em âmbito global, o que é definido por Passetti (2013) e Rodrigues (2013) como uma governamentalidade planetária. No curso "Segurança, Território e População", Foucault (2008) aborda o nascimento do que ele denomina como governamentalidade, enquanto forma de compreender como o poder é exercido, a partir da análise de práticas de governo. Segundo ele, desde o século XVII a administração das populações foi desenvolvida sob o triângulo "soberania, disciplina e gestão governamental”, havendo, nesse sentido, uma gestão na qual o "alvo principal é a população e cujos mecanismos são os dispositivos de segurança" (FOUCAULT, 2008, p. 143). O modo de governar e as técnicas de governo - entendidas por Foucault como governamentalidade - foram fundamentais para a sobrevivência do Estado. Para ele, "se o Estado é o que é hoje, é graças a esta governamentalidade, ao mesmo tempo interior e exterior" (FOUCAULT, 2016, p. 460). Dessa forma, a perspectiva da governamentalidade propiciaria o reconhecimento de "como" e "quem" produz conhecimento sobre as práticas de governo (condução das condutas) de determinado território e sua população. Por exemplo, ao analisar o processo de governamentalidade a partir de meados do século XVIII, Foucault verificou como ocorreu a absorção dos "saberes estatísticos e da ciência política no governo da população, as reformas urbanísticas, as políticas de saúde e a medicina social, as regulamentações do trabalho", além de novos dispositivos para "comandar a circulação de pessoas e coisas" (PASSETTI, 2013, p. 3).

Partindo dessa perspectiva, é possível discutir as facetas contemporâneas e planetárias da concepção de governamentalidade, enquanto um conjunto atual de investimentos, procedimentos e táticas alinhadas às institucionalizações e gestões diante das novas ameaças à segurança global (a partir da justificativa de promoção da conservação do meio ambiente, garantia dos direitos humanos, combate aos tráficos transterritoriais, combate à pobreza extrema, controle das migrações massivas e das epidemias em larga escala, entre outros). Entende-se que a aplicação da noção de governamentalidade para a compreensão das relações de poder em âmbito global na contemporaneidade contribui para a identificação de como as novas ameaças transterritoriais (como seria o caso do terrorismo fundamentalista) e a implementação de determinado modelo democrático-liberal de governo são tidos enquanto objetivos a serem compartilhados e executados por toda a comunidade internacional.

Especificamente em relação ao terrorismo contemporâneo, evidencia-se a criação de dispositivos de segurança que visavam a táticas para governar que teriam abrangência em uma escala planetária, buscando produzir condutas e trazer certa previsibilidade alinhadas aos interesses de determinados países. Essa abrangência no combate é resultado da percepção de uma "luta contra o terrorismo em escala global”, pois o inimigo não é representado por uma pessoa ou um simples 
regime político, e sim por terroristas que premeditadamente perpetrariam ataques violentos a pessoas inocentes (NSS, 2002, p. 5).

A partir desta perspectiva, segundo Duarte (2014, p. 102), “projeta-se uma nova governamentalidade que pouco a pouco se estabelece, e que se acopla às relações internacionais para fazer do planeta e de todos dentro dele o ponto central de investimento de seu poder". Nesse sentido, a formulação do conceito de inimigo combatente é fruto de um processo de veridicção que possibilita o estabelecimento de uma série de dispositivos de controle na política mundial, desenvolvidos a partir de uma lógica de "divisão binária entre nós e eles, sendo eles a nova encarnação do anormal, redimensionado, na contemporaneidade, a uma sociedade globalizada” (idem, p. 64-65).

Em seu texto "Lines of Insecurity: International, Imperial, Exceptional", Walker (2006) destaca que a vida política moderna ainda é realizada a partir do binômio "bárbaros" versus "modernos", um artifício responsável por decidir sobre quem pode ser tratado como ser humano propriamente dito, e a quem não cabe a participação na ordem internacional contemporânea por não estar apto a ser reconhecido como um membro legítimo da comunidade internacional. Escrevendo em meio à Guerra ao Terror, Walker (2006) sugere como o combate aos terroristas islâmicos reforçaria uma antiga produção de alteridades nas relações internacionais. As ações de diversos representantes do Ocidente no pós-11/o9 seriam mais uma amostra de como constituemse os termos para inclusão/exclusão daqueles "Outros" que atuam à revelia do que é considerado a legítima vida política moderna.

Mais recentemente, vimos a dupla tentativa de dar prioridade (altamente seletiva) a valores supostamente internacionais (geralmente entendidos como humanitários ou simplesmente universais) sobre o princípio da não intervenção, e a tentativa relacionada de enquadrar vários povos como bárbaros, que estariam além dos limites do moderno/internacional (a figura do terrorista islâmico) (WALKER, 2006, p. 72).

Nessa perspectiva, Duarte (2014) aponta para uma nova espécie de sujeito perigoso, retomando a ideia de anormal presente nas análises de Foucault em relação à sociedade disciplinar nos séculos XVIII e XIX, na qual esse sujeito representava uma ameaça aos bons costumes e à normalidade. Essa interpretação em relação à anormalidade se torna preponderante, pois, supondo que os terroristas e aliados do terror são "inimigos da civilização", como destaca a NSS (2002, p. 31), conclui-se que este sujeito promove uma ameaça não apenas a princípios como liberdade e democracia, mas à humanidade em si.

Portanto, para os policy-makers estadunidenses a percepção do terrorista como inimigo da civilização ocidental é embasada pela lógica de combate entre civilizados e bárbaros. Segundo a NSS (2002, p. 31), a Guerra ao Terror não seria um choque de civilizações e sim um choque dentro da civilização (NSS, 2002, p. 31). Dentro dessa perspectiva, em discurso proferido em 20 de setembro de 2001, no Joint Session of Congress and American People, George W. Bush declarou que a luta não seria apenas da América, e não apenas de sua liberdade, mas uma luta mundial. Uma luta 
civilizacional de todos que acreditam no progresso e no pluralismo, na tolerância e liberdade (BUSH, 2001). Ressalta-se que o então Secretário de Estado norte-americano, Colin Powell, em 13 de setembro de 2001, já havia afirmado que "o terrorismo é um crime contra toda civilização [...] contra toda humanidade" (POWELL, 2001a), reiterando sua visão no dia seguinte, ao dizer na imprensa que Osama bin Laden estava atacando a civilização (POWELL, 2001b).

A partir desta lógica, as políticas promovidas pelos EUA estabeleceriam uma ofensiva civilizacional na qual a questão da guerra passaria a ser vista, cada vez mais, como uma ação policial. Segundo Mark Neocleous (2011, p. 144), a Guerra ao Terror seria uma "combinação violenta de guerra e polícia”, na qual os EUA teriam como função dentro do sistema internacional promover o retorno à civilização, a partir do desenvolvimento de um policiamento eficaz no combate ao terror. Para Neocleous (2011), essa percepção da civilization-as-police teria influência direta na fabricação da atual ordem internacional.

Todavia, salienta-se que a construção deste sujeito perigoso é mutável. Isto quer dizer que, devido aos saberes sujeitados - em outras palavras, os "conteúdos históricos que foram sepultados, mascarados em coerências funcionais ou em sistematizações formais" (FOUCAULT, 2005, p. 11) - o processo de veridicção culmina em uma produção na qual a figura do terrorista fundamentalista é vista como uma ameaça existencial7, enquanto outras percepções sobre o assunto ficam bastante inacessíveis.

A construção deste discurso estadunidense, que se afirma imparcial e universal, possibilita a realização de uma guerra justa na qual os combatentes inimigos, segundo Duarte (2014, p 65), "passaram a ser identificados dessa maneira como forma de facilitar o seu aprisionamento", sem qualquer direito de defesa. Além disso, as instituições tentavam "justificar a normalização da prática de tortura dentro das prisões criadas para abrigá-los, uma ferramenta imprescindível na obtenção de informações sobre novos terrorismos e sobre o esconderijo de grandes terroristas".

Essa desumanização dos prisioneiros de guerra infringia diretamente as normativas estabelecidas pela Convenção de Genebra sobre o Tratamento de Prisioneiros de Guerras (1949). Para Rubens Barbosa (2011), as medidas extraordinárias implementadas pelos EUA explicitam as contradições quanto à participação desse país no processo histórico de construção e/ou defesa de certos valores. A exemplificação trazida pelo autor volta-se à questão dos direitos humanos, que foram, novamente, relativizados em nome da segurança nacional. No pós-11/o9, qualquer pessoa suspeita de cometer atos terroristas poderia ser detida pelo governo sem a possibilidade de recorrer ao direito de habeas corpus, por exemplo. Assim, os prisioneiros acusados de terrorismo tornaramse juridicamente desamparados, e passaram a ser suscetíveis ao arbítrio do governo estadunidense em relação ao campo do direito individual. Neste liame, as instalações da base militar de Guantánamo passaram a ser utilizadas como prisões especiais para confiná-los.

\footnotetext{
7 Um exemplo é a ressignificação do próprio Osama bin Laden, pois a visão estadunidense em relação a ele migrou da posição de aliado para inimigo terrorista em decorrência dos interesses norte-americanos.
} 
Juridicamente, o Patriot Act funcionava como um aparato institucional de vigilância destes corpos considerados anormais, fornecendo condições para "prevenir, investigar e julgar atos de terror" (US PATRIOT ACT, 2001). Primeiramente, no campo da prevenção e da investigação, o Ato Patriota permitia a potencialização de ferramentas já disponíveis para investigação e a ampliação de leis voltadas às novas tecnologias de monitoramento. Além disso, buscava facilitar 0 compartilhamento e cooperação entre as agências governamentais para melhor "conectar os pontos". Por fim, quanto ao fato de julgar os atos de terror, era previsto o aumento de penalidades para os indivíduos que cometessem crimes terroristas (US PATRIOT ACT, 2011).

Dessa forma, a governamentalidade estabelecida na Guerra ao Terror transcende o âmbito interno. Em um período de transnacionalização dos conflitos, ocorre também a transnacionalização das burocracias das agências de controle (MARTINS e AMARAL, 2017), identificadas pelas "práticas de excepcionalismo, na caracterização e contenção de estrangeiros e na normatização da mobilidade" (BIGO, 2008, p. 10). À vista dessas construções burocráticas implementadas, em especial, pelos EUA, é possível considerar que a postura internacional desse país é embasada em uma formulação discursiva, estruturada em premissas universais, que legitima um novo papel para este Estado, diante da reformulação da ideia de segurança internacional desde o final da Guerra Fria.

Sendo assim, esta governamentalidade planetária gerada com o intuito de produzir condutas, tanto interna quanto externamente, é resultado de um imbricamento destas esferas em um contexto contemporâneo. A problemática analítica trazida pelo terrorismo, isto é, a dificuldade de compreender sua lógica sob um prisma dicotômico entre interno e externo, também era percebida pelos policy-makers estadunidenses, como evidenciado na NSS (2002, p.31): a "distinção entre o doméstico e as relações externas está diminuindo. Logo, em um mundo globalizado, os eventos além das fronteiras americanas possuem grande impacto dentro delas".

A necessidade de analisar questões semelhantes ao terrorismo fundamentalista para além da lógica de divisão rígida entre a internalidade (inside) e a externalidade (outside), a qual tanto permeia as produções das teorias tradicionais de Relações Internacionais, já havia sido apontada por autores como Walker (2013). A demarcação de interno (inside) e externo (outside); Self e Outro; identidade e diferença; comunidade e anarquia; evidencia a forma pela qual o espaço político ainda é entendido em sua concepção moderna, o que limita a compreensão das questões que caracterizam a segurança global contemporânea (WALKER, 2013, p. 255).

Quando Foucault (2001, p. 86) nos alerta que "no pensamento e na análise política ainda não cortaram a cabeça do rei", ele ressalta que a Razão de Estado (vigente a partir do século XVI) ainda está presente nas reflexões contemporâneas sobre a atuação dos Estados. Segundo Foucault (2008, p. 491-492), o sistema geral de segurança produzido pela razão governamental moderna aperfeiçoou duas ferramentas codependentes de saber e de tecnologia política. A primeira é o dispositivo diplomático-militar (um dos princípios basilares do Tratado de Vestfália), voltado ao fortalecimento do Estado frente aos seus pares, oferecendo melhores condições de alianças estratégicas e de um 
forte aparelho armado. A segunda é o desenvolvimento do princípio da polícia que, no sentido que se dava ao termo, significava o aprimoramento de instrumentos que fortalecessem internamente o Estado.

Todavia, as questões que caracterizam a segurança internacional contemporânea demonstram a dificuldade de análises que não estão atentas para as aproximações entre esses dispositivos, os quais caracterizariam atividades próprias aos âmbitos interno e externo dos Estados. Atualmente, os dispositivos diplomático-militar e o de polícia operariam "em conjunto, de modo articulado, como um só dispositivo a fim de preservar o Estado" (RODRIGUES, 2013, p. 134). Dessa forma, o caráter transterritorial do terrorismo fundamentalista tornou-se um problema para as análises mais tradicionais de segurança internacional. Sendo assim, a argumentação trazida por Walker (2013), de uma relação coconstitutiva entre internalidade e externalidade, ajuda na compreensão da atual constituição de práticas que visam à regulamentação do dispositivo de polícia em âmbito global.

Assim, compreendendo esse dispositivo de polícia a partir da lógica de regulamentação de condutas, um novo dispositivo estaria emergindo, agora em dimensão planetária, chamado, por Rodrigues (2013), de dispositivo diplomático-policial. Essa técnica rememora o sentido fornecido à "polícia” na emergência da Razão de Estado entre os séculos XVI e XVII - a qual recuperava elementos do chamado poder pastoral, ao ser composta por uma série de instrumentos que buscavam intervir em todos os campos de interesse e atuação da população. Não há a negação da função repressora da polícia (mais próxima da acepção deste termo na governamentalidade liberal, após o século XVIII), mas ela é apenas um componente dentro de uma dinâmica ampla de produção de condutas. O elemento "policial" desse novo dispositivo não reportaria, dessa forma, ao mero sentido negativo da polícia atrelada ao despontar da biopolítica, mas recuperaria a "polícia" enquanto regulamentação minuciosa e perene das condutas, dessa vez, em escala global.

Diante dessa dinâmica, a projeção dos EUA e a operacionalização dos mecanismos de controle são efeitos do estabelecimento de regimes de verdade de insegurança (BIGO, 2008). O processo de veridicção, ou seja, a construção de regimes de verdade, agora transterritorializados, acarreta sentimentos de (in)segurança, e a partir do "combate às atividades que 'legitimam' o medo e a insegurança nacional, verifica-se que os profissionais da (in)segurança criam estratégias para extrapolar os limites territoriais” (MARTINS e AMARAL, 2017, p. 166). Nessa dinâmica de policiamento globalizado, o controle populacional ocorre a partir da "elaboração de perfis traçados não necessariamente pelo poder punitivo, mas numa roupagem burocrática/administrativa" (MARTINS e AMARAL, 2017, p. 167)

O caráter geopolítico também é fundamental para a análise das políticas estadunidenses em sua Guerra ao Terror. Segundo Dillon (2007), as políticas teriam um perfil tanto biopolítico quanto geopolítico. Em outras palavras, seria uma combinação entre ambos, e esta biopolitização serviria como um dispositivo de segurança para regular e manipular a circulação dos indivíduos. A percepção 
geopolítica também é salientada por Duarte (2014), o qual ressalta que, após os atentados de 11/o9, a atenção com a segurança se direcionou para áreas consideradas não tradicionais dentro da geopolítica, ao visar países que eram considerados zonas com déficit de governança e teriam como potencial tornarem-se uma ameaça terrorista. A National Security Strategy (2002) previa um suporte para o estabelecimento de governos modernos, principalmente no mundo islâmico, como forma de assegurar condições e ideologias que possam promover uma estrutura para que o “terrorismo não encontre solo fértil em nenhuma nação" (NSS, 2002, p.6).

O Afeganistão foi utilizado pelos EUA para estruturar esse discurso em sua Estratégia de Segurança Nacional. Na NSS (2002), os tomadores de decisão estadunidenses atentaram para o fato de que:

Os eventos de 11 de setembro de 2001 nos ensinaram que Estados fracos, como o Afeganistão, podem representar um grande perigo aos nossos interesses nacionais como Estados fortes. Pobreza não torna pessoas pobres em terroristas e assassinos. Ainda assim, pobreza, instituições fracas e corrupção podem fazer com que Estados fracos sejam vulneráveis às redes terroristas e cartéis de drogas dentro de suas fronteiras. (NSS, 2002, n.p).

O caso do Afeganistão, na visão de autores como Fukuyama (2005), seria um exemplo de Estado falido, ou seja, uma unidade política que era formalmente independente, mas não teria o efetivo controle das funções administrativas, jurídicas e coercitivas que caracterizariam o poder estatal em determinado território. Para Fukuyama (2005), Estados como o Afeganistão seriam a fonte de graves problemas de segurança internacional, tais como o terrorismo internacional. Ou seja, a al-Qaeda teria sido fomentada devido à falta de estruturas estatais fortes na região do Oriente Médio. Para o autor, os ataques terroristas de 11/o9 seriam a prova mais cabal de que a fraqueza de poucos Estados afetaria a segurança de todos os outros, havendo, portanto, a urgência por intervir e reconstruir as unidades políticas consideradas frágeis. Logo, a intervenção implementada pelos EUA teria como meta reparar e, consequentemente, construir novas bases para aquele Estado. Nesta construção de discursos de verdade, a ideia de justa causa, conforme apregoam autores como Michael Walzer (2003), é retomada com o intuito de legitimar ações de intervenção sob o argumento de "corrigir" determinados Estados em prol da segurança global.

Essas ideias são refletidas na percepção estadunidense de sua “missão”, em conjunto com outros Estados e Organizações Internacionais, de "prover assistência humanitária, política, econômica e segurança necessária para reconstruir o Afeganistão" para que "nunca mais abusem de seu povo, ameacem seus vizinhos e proveja abrigo para terroristas" (NSS, 2002, p. 7). Posteriormente, esse processo de estabilização também será alvo da governamentalidade estadunidense em 2003, no caso do Iraque. A possibilidade da aquisição de armas de destruição em massa por parte de grupos terroristas era uma preocupação do governo dos EUA, e este fator se torna evidente na própria NSS (2002), a qual previa que o país não poderia permitir que esse processo se concretizasse. Os casos do Afeganistão (2001) e do Iraque (2003) representam essa luta que os EUA 
travaram com os grupos considerados terroristas que ameaçavam seus valores fundamentais e, por isso, o país "não faria concessões para demandas terroristas" (NSS, 2002, p.5). Nesse embate, a prioridade dos EUA seria "destruir organizações terroristas de escala global e atacar seus líderes”, sem estabelecer "distinções entre terroristas e quem provem ajuda para eles" (Ibidem).

Portanto, nesta governamentalidade planetária os EUA e seus aliados buscam produzir condutas interna e externamente. O dispositivo diplomático-policial tem redimensionado o policiamento à dimensão global, combinando práticas de violência explícita com um rol de ações de ajuda internacional e monitoramento que visam a gerir os Estados com governança fraca e os sujeitos considerados perigosos. Assim, a formulação deste dispositivo de segurança planetária se tornou um fator preponderante na formulação das políticas de segurança estadunidenses, em prol de um maior poder de ingerência na sociedade civil global.

\section{CONSIDERAÇÕES FINAIS}

Neste artigo o principal objetivo foi analisar o processo de veridicção, relacionado à construção de "regimes de verdade", que caracteriza a transformação do terrorismo no principal problema de segurança dos EUA durante o governo Bush. A partir dessa proposta, buscou-se salientar que, com a eclosão do terrorismo fundamentalista - um fenômeno de caráter não convencional, transterritorial e descentralizado -, foi estruturada uma governamentalidade planetária, que buscou formas de legitimar ações de repressão, prevenção e controle sobre determinados grupos e populações.

Foi possível verificar que o processo de veridicção na afirmação do terrorismo enquanto principal ameaça à governança global no início do século XXI culmina no estabelecimento de novos dispositivos que geram um policiamento em ambiente planetário. Assim, o fortalecimento do status de verdade para determinados discursos permite a materialização de práticas que permitem policiar condutas (dispositivo diplomático-policial) em prol de uma segurança planetária.

Neste artigo, buscou-se apresentar questões a serem verificadas e ampliadas em pesquisas futuras sobre o debate em torno de como a produção de regimes de verdade se relaciona com as atuais ações relacionadas à segurança internacional, em específico no que tange ao terrorismo. Entendemos que a perspectiva analítica utilizada neste texto pode ser apropriada para análises futuras sobre as atuais configurações das relações de poder que conformam o terrorismo contemporâneo, após cerca de vinte anos de estabelecimento da Guerra ao Terror.

*Artigo recebido em 04 de julho de 2020, aprovado em 22 de novembro de 2020. 


\section{REFERÊNCIAS}

BUSH, George. Address before a Joint Session of the Congress on the United States Response to the Terrorist Attacks of September 11. 20 September. Disponível em: <https://www.presidency.ucsb.edu/documents/address-before-joint-session-the-congress-theunited-states-response-the-terrorist-attacks >. Acesso: 13 de Dez. 2020.

BARBOSA, Rubens. O Dissenso de Washington: Notas de um observador privilegiado sobre as relações Brasil-Estados Unidos. Nova Fronteira, Rio de Janeiro, 2011.

BIGO, Didier. Terror, Insecurity and Liberty. Routledge, New York, 2008.

CLAUSEWITZ, Carl von. On War. Princeton: Pricenton University Press, 1989.

CHOMSKY, Noam. Hegemony or Survival: America's Quest for Global Dominance. New York: Henry Holt and Company, 2003.

DILLON, Michael. Governing Terror: The State of Emergency of Biopolitical Emergence. International Political Sociology, no. 1, 2007, p. 7-28.

DUARTE, João Paulo. Terrorismo: caos, controle e segurança. Desatino, Rio de janeiro, 2014.

FOUCAULT, Michel. O Sujeito e o Poder". In: RABINOW, P.; DREYFUS, H. Michel Foucault, uma trajetória filosófica. Rio de Janeiro: Forense Universitária, 1995.

FOUCAULT, Michel. História da sexualidade, Volume 1: A Vontade de saber. Rio de Janeiro: Graal, 2001.

FOUCAULT, Michel. Em Defesa da Sociedade. São Paulo: Martins Fontes, 2005.

FOUCAULT, Michel. Segurança, Território e População. São Paulo: Martins Fontes, 2008.

FOUCAULT, Michel. Do governo dos vivos. Curso no Collège de France, 1979-1980 (excertos). Rio de Janeiro: Achiamé, 2010a.

FOUCAULT, Michel. O governo de si e dos outros. São Paulo: Martins Fontes, 2010b.

FOUCAUlT, Michel. Microfísica do Poder. Rio de Janeiro: Paz e Terra, 2016.

FUKUYAMA, Francis. O Fim da História e o Último Homem. Rio de Janeiro: Rocco, 1992.

FUKUYAMA, Francis. Construção de Estados: governo e organização no século XXI. Rio de Janeiro: Rocco, 2005.

GARDELL, Mattias. Torture, Terror and Truth: On the Meaning of Guantánamo and the Future of Global Order. Temenos, vol. 44, n. 1, 2008, p. 139-164. Disponível em: <https://journal.fi/temenos/article/view/4603/6784>. Acesso em: 13 Dez. 2020.

KALDOR, Mary. New and Old Wars: Organised Violance in Global Era. UK: Policy Press, 2012.

MARTINS, Fernanda; AMARAL, Augusto. Exceção, Governamentalidade e Políticas de Segurança. FDV publicações, v. 18, n. 2, p. 153-178, 2017, p. 153-177.

NEOCLEOUS, Mark. The Police of Civilization: The War on Terror as Civilizing Offensive. International Political Sociology, n. 5, 2011, p. 144-159. 
NSS - THE NATIONAL SECURITY STRATEGY, 2002. Disponível em: < https://georgewbushwhitehouse.archives.gov/nsc/nss/2002/>. Acesso em: 13 Dez. 2020.

PASSETTI, Edson. Transformações da biopolítica e emergência da ecopolítica. Ecopolítica, v. 5, São Paulo: PUCSP, jan-abr, 2013, p. 02-37.

POWELL, Colin. Remarks to the Press. September 13, 2001a. Disponível em: <https://avalon.law.yale.edu/sept11/powell briefo1.asp> Acesso em: 13 Dez. 2020.

POWELL, Colin. Remarks to the Press. Setember 14, 2001b. Disponível em: < https://avalon.law.yale.edu/sept11/powell briefo5.asp> Acesso em: 13 Dez. 2020.

PNUD, Programa das Nações Unidas para o Desenvolvimento. Novas Dimensões da Segurança Humana. Relatório do Desenvolvimento Humano, Nova Iorque, EUA, 1994.

PROCÓPIO, Argemiro. Terrorismo e relações internacionais. Revista Brasileira de Política Internacional, vol. 44, no. 2, Brasília, Jul-Dez 2001. Disponível em: $<$ https://www.scielo.br/scielo.php?script=sci arttext\&pid=So034-73292001000200004 $>$. Acesso em: 13 Dez. 2020.

RODRIGUES, Thiago. KALIL FILHO, Marcos. Discursos, verdade e linguagem: indicações metodológicas para as RI. In: SIQUEIRA, I; MAGALHÃES, B; CASTELO-BRANCO, T; GRANDA, S. Metodologia e relações internacionais: debates contemporâneos. Rio de Janeiro, 2018.

RODRIGUES, Thiago. Ecopolítica e segurança: a emergência do dispositivo diplomático-policial. Ecopolítica, v. 5, 2013, p. 117-158.

SEIXAS, Eunice Castro. "Terrorismos": uma exploração conceitual. Revista de Sociologia e Política, vol. 16, Curitiba, 2008. Disponível em: <https://www.scielo.br/scielo.php?script=sci arttext\&pid=S0104-44782008000300002>. Acesso em: 13 Dez. 2020.

US PATRIOT ACT. Disponível em: <https://www.justice.gov/archive/ll/highlights.htm>. Acesso em: 13 Dez. 2020.

WALKER, Rob. Inside/Outside: Relações Internacionais como teoria política. Rio de Janeiro: Editora PUC-Rio, 2013.

WALKER, Rob. Lines of Insecurity: International, Imperial, Exceptional. Security Dialogue, v. 37, n. 1, 2006, p. 65-82.

WALZER, Michael. Guerras Justas e Injustas. São Paulo: Martins Fontes, 2003.

YAZBEK, André. Poder, Política e Verdade em Michel Foucault: notas sobre as implicações práticas do discurso. Revista Olhar, n. 28, Jan/Jun. 2013, p. 91-101. 